Check for updates

Cite this: RSC Adv., 2019, 9, 39699

Received 14th October 2019

Accepted 14th November 2019

DOI: 10.1039/c9ra08391j

rsc.li/rsc-advances

\section{Enhancement of $\mathrm{NH}_{3}$-SCR performance of $\mathrm{LDH}-$ based MMnAl ( $\mathrm{M}=\mathrm{Cu}, \mathrm{Ni}, \mathrm{Co}$ ) oxide catalyst: influence of dopant $\mathrm{M} \dagger$}

\begin{abstract}
Yali Du, $\ddagger^{\mathrm{a}}$ Lili Liu, $\ddagger^{\mathrm{b}}$ Yalin Feng, ${ }^{\mathrm{b}}$ Baoshuan Yang (D) ${ }^{\mathrm{b}}$ and $\mathrm{Xu}$ Wu (D) *b
Transition metal $(\mathrm{Cu}, \mathrm{Ni}, \mathrm{Co})$ doped $\mathrm{MnAl}$ mixed oxide catalysts were prepared through a novel method involving the calcination of hydrotalcite precursors for the selective catalytic reduction of $\mathrm{NO}_{x}$ with $\mathrm{NH}_{3}$ $\left(\mathrm{NH}_{3}-\mathrm{SCR}\right)$. The effects of transition metal modification were confirmed by means of XRD, BET, TEM, XPS, $\mathrm{NH}_{3}$-TPD, and $\mathrm{H}_{2}$-TPR measurements. Experimental results evidenced that CoMnAl-LDO presented the highest $\mathrm{NO}_{x}$ removal efficiency of over $80 \%$ and a relatively high $\mathrm{N}_{2}$ selectivity of over $88 \%$ in a broad working temperature range $\left(150-300{ }^{\circ} \mathrm{C}\right)$ among all the samples studied. Moreover, the COMnAl-LDO sample possessed better stability and excellent resistance to $\mathrm{H}_{2} \mathrm{O}$ and $\mathrm{SO}_{2}$. The reasons for such results could be associated with the good dispersion of $\mathrm{CO}_{3} \mathrm{O}_{4}$ and $\mathrm{MnO}_{x}$, which could consequently provide optimum redox behavior, plentiful acid sites, and strong $\mathrm{NO}_{x}$ adsorption ability. Furthermore, dynamics calculations verified the meaningful reduction in apparent activation energy $\left(E_{\mathrm{a}}\right)$ for the CoMnAl-LDO sample, which is in agreement with the DeNO ${ }_{x}$ activity.
\end{abstract}

\section{Introduction}

Nitric oxide $\left(\mathrm{NO}_{x}\right)$, which is mainly generated from stationary and automotive sources, has definitely given rise to many problems for the environment and has resulted in health concerns for humans..$^{1-3}$ With gradually tightening regulations on $\mathrm{NO}_{x}$ emission limits, post-treatment of nitrogen oxides has become one of the most important research challenges the world faces today in the environmental domain. Currently, selective catalytic reduction (SCR) has been put into wide commercial utilization to abate $\mathrm{NO}_{x}{ }^{4-6}$ Most practical catalysts in the SCR system are vanadium-based catalysts that must be installed upstream of dedusting and desulfurization to satisfy their optimal operating temperature of $300-400{ }^{\circ} \mathrm{C}$ or the catalysts could be poisoned by high concentrations of dust particles and sulfur-containing ammonium salts. ${ }^{7-9}$ In this situation, it is necessary to develop low-temperature and environmentally friendly catalysts which can efficiently work in the downstream and avoid those problems mentioned above.

Mn-based DeNO$_{x}$ catalysts have been extensively explored in the low-temperature $\mathrm{NH}_{3}$-SCR field due to their unique redox properties, as they are sensitive to $\mathrm{H}_{2} \mathrm{O}$ and $\mathrm{SO}_{2} \cdot{ }^{10,11}$ To

\footnotetext{
${ }^{a}$ College of Chemistry and Chemical Engineering, Jinzhong University, Jinzhong, 030619, PR China.E-mail:dylo037@163.com

${ }^{b}$ College of Chemistry and Chemical Engineering, Taiyuan University of Technology, Taiyuan 030024, PR China. E-mail: wuxu@tyut.edu.cn; Tel: +86-351-6018528

$\dagger$ Electronic supplementary information (ESI) available. See DOI: $10.1039 /$ c9ra08391j

\$ These authors contributed equally to this work.
}

overcome these issues, transition metals have been introduced to Mn-based catalysts to modulate their redox ability and acid sites. ${ }^{12-14}$ For example, Qiu successfully designed $\mathrm{Mn}_{x} \mathrm{Co}_{3-x} \mathrm{O}_{4}$ nanoparticles through nanocasting, which presented superior catalytic performance to bulk $\mathrm{MnCo}_{2} \mathrm{O}_{4}$ synthesized through the co-precipitation method. ${ }^{15}$

In recent years, calcined layered double hydroxides (LDHs) have shown potential use as catalysts for several reasons, such as the possibility of tuning the composition in wide scope, their high surface areas and homogenous distribution of introduced cations. ${ }^{16-18}$ In addition, $\mathrm{Al}$ was proved to be of great necessity to enhance the self-stability of the LDH materials. From LDH precursors, Yan et al. ${ }^{19}$ prepared $\mathrm{Cu}_{0.5} \mathrm{Mg}_{1.5} \mathrm{Mn}_{0.5} \mathrm{Al}_{0.5} \mathrm{O}_{x}$, which presented superior catalytic performance in a wide temperature range compared to $\mathrm{Mn} / \gamma-\mathrm{Al}_{2} \mathrm{O}_{3}$ prepared by conventional methods. This method might enable good dispersion of the active metal species to provide strong internal interactions for the $\mathrm{Cu}_{0.5} \mathrm{Mg}_{1.5} \mathrm{Mn}_{0.5} \mathrm{Al}_{0.5} \mathrm{O}_{x}$ catalyst.

Based on the abovementioned points, using LDHs own innate advantages to accomplish the effective doping of transition metal into MnAl oxides could facilitate $\mathrm{DeNO}_{x}$ performances. Herein, $\mathrm{Cu}-$, Ni- or Co-doped $\mathrm{MnAl}$ mixed metal oxide catalysts were investigated for $\mathrm{NH}_{3}$-SCR at low temperatures, taking into account the characterization results of XRD (X-ray diffraction), BET (Brunauer-Emmett-Teller), XPS (X-ray photoelectron spectroscopy), $\mathrm{NH}_{3}$-TPD $\left(\mathrm{NH}_{3}\right.$-temperature programmed desorption), $\mathrm{H}_{2}$-TPR $\left(\mathrm{H}_{2}\right.$-temperature programmed reduction), $\mathrm{NO}+\mathrm{O}_{2}$-TPD ( $\mathrm{NO}+\mathrm{O}_{2}$-temperature programmed desorption), etc. The addition of Co into MnAl oxide is proposed to dramatically increase its catalytic ability and behaviour, as 
CoMnAl-LDO presented preferable DeNO $_{x}$ activity (over 80\% NO conversion) and $\mathrm{N}_{2}$ selectivity in a broad working temperature window (150-300 $\left.{ }^{\circ} \mathrm{C}\right)$. In addition, the CoMnAl-LDO sample possessed better stability and excellent resistance to $\mathrm{H}_{2} \mathrm{O}$ and $\mathrm{SO}_{2}$ at $240{ }^{\circ} \mathrm{C}$.

\section{Experimental section}

\subsection{Preparation of MMnAl-LDO $(\mathrm{M}=\mathrm{Cu}, \mathrm{Ni}, \mathrm{Co})$}

The MMnAl-LDH $(\mathrm{M}=\mathrm{Cu}, \mathrm{Ni}$, and $\mathrm{Co})$ materials were prepared by co-precipitation method. $50 \% \mathrm{Mn}\left(\mathrm{NO}_{3}\right)_{2}, \mathrm{Al}\left(\mathrm{NO}_{3}\right)_{3} \cdot 9 \mathrm{H}_{2} \mathrm{O}$ and $\mathrm{Cu}\left(\mathrm{NO}_{3}\right)_{2} \cdot 3 \mathrm{H}_{2} \mathrm{O}$ (or Ni($\left.\left(\mathrm{NO}_{3}\right)_{2} \cdot 6 \mathrm{H}_{2} \mathrm{O}, \mathrm{Co}\left(\mathrm{NO}_{3}\right)_{2} \cdot 6 \mathrm{H}_{2} \mathrm{O}\right)$ were dissolved in deionized water, in which the molar ratios of $\mathrm{M}^{2+}$ to $\mathrm{Mn}^{2+}$ and $\mathrm{M}^{2+}$ to $\mathrm{M}^{3+}$ were $3: 1$ and $4: 1\left(\mathrm{M}^{2+} / \mathrm{Mn}^{2+}=3\right.$ and $\mathrm{M}^{2+} /$ $\mathrm{M}^{3+}=4: 1$ ), respectively. Then, the above aqueous solution was added into $1 \mathrm{~mol} \mathrm{l}^{-1} \mathrm{NaOH}$ solution with vigorous stirring. In order to avoid oxidation of $\mathrm{M}^{2+}, \mathrm{N}_{2}$ was injected during the whole aging process. The $\mathrm{pH}$ of the solution was kept at 9-10. The resulting slurry was transferred into a reaction vessel for about $6 \mathrm{~h}$ at $60^{\circ} \mathrm{C}$. Finally, MMnAl-LDH ( $\mathrm{M}=\mathrm{Cu}, \mathrm{Ni}$, and Co) materials were obtained by drying at $60^{\circ} \mathrm{C}$ overnight in an oven. After being calcined at $500{ }^{\circ} \mathrm{C}$ for $5 \mathrm{~h}$ at a rate of $2{ }^{\circ} \mathrm{C} \mathrm{min}{ }^{-1}$ in air, diverse mixed metal oxides were prepared which were labelled CuMnAl-LDO, NiMnAl-LDO and CoMnAl-LDO. Meanwhile, the MnAl-LDH and corresponding MnAl-LDO were prepared by a similar method.

\subsection{Catalyst characterization}

The X-ray diffraction (XRD) patterns for pristine hydrotalcites and corresponding mixed metal oxides were tested with a Rigaku D/max-2500 diffractometer with a $\mathrm{Cu} / \mathrm{K} \alpha$ radiation source. The operating range for $2 \theta$ was from 5 to $85^{\circ}$ and the scanning rate was $8^{\circ} \mathrm{min}^{-1}$. FT-IR experiments were carried out on an FTS 3000 MX FT-IR (Bruker Vertex70) spectrophotometer. The morphologies of the obtained hydrotalcites were measured by an SU8010 SEM apparatus with an accelerating voltage of $200 \mathrm{kV}$. TEM was carried out on a JEM $2100 \mathrm{~F}$ transmission electron microscope. The TGA was performed on a Q50 TGA analyzer equipped with a quadrupole mass spectrometer (QMS). The range of testing temperature was from room temperature to $900{ }^{\circ} \mathrm{C}$ in flowing $\mathrm{Ar}\left(80 \mathrm{~mL} \mathrm{~min}^{-1}\right)$ at the heating rate of $10^{\circ} \mathrm{C} \mathrm{min}^{-1}$. The surface areas for hydrotalcitederived mixed oxides were obtained via the BET method. The operating instrument was a Micromeritics ASAP-2020 which needs $-196{ }^{\circ} \mathrm{C}$ liquid nitrogen during operation. In addition, the $t$-plot approach was used to analyze the total pore volume and the pore size distributions were analyzed by BJH (BarrettJoyner-Halenda) method. $\mathrm{H}_{2}$-TPR was performed in a TP-5080 instrument. A U-shaped quartz reactor is filled with $80 \mathrm{mg}$ catalyst (40-60 mesh). Before operation, the samples were activated at $300^{\circ} \mathrm{C}$ for $1 \mathrm{~h}$ under Ar flow. Next, the temperature of the catalyst was decreased to room temperature. Then the catalyst was heated to $800{ }^{\circ} \mathrm{C}$ with a ramping rate of

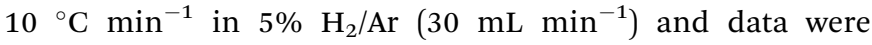
collected during the process. For $\mathrm{NH}_{3}$-TPD, the amount of catalyst and the initial activation process were the same as $\mathrm{H}_{2}-$
TPR. Next, unlike the $\mathrm{H}_{2}$-TPR, the catalyst was exposed to $\mathrm{NH}_{3}$ at $50{ }^{\circ} \mathrm{C}$ for $1 \mathrm{~h}$, followed by removing unstably adsorbed species by blowing $\mathrm{He}$ for $30 \mathrm{~min}$. Then, the desorption process of $\mathrm{NH}_{3}$ was performed with the temperature of the reactor rising to $750{ }^{\circ} \mathrm{C}$ at a rate of $10{ }^{\circ} \mathrm{C} \mathrm{min}^{-1}$. $\mathrm{NO}+\mathrm{O}_{2}$-TPD experiments were operated on a fixed bed reactor selfassembled in the laboratory. First, the catalyst was pretreated at $300{ }^{\circ} \mathrm{C}$ under $\mathrm{N}_{2}$ flow for $1 \mathrm{~h}$. Then, adsorption of $5 \mathrm{vol} \% \mathrm{O}_{2}$ and $500 \mathrm{ppm} \mathrm{NO}$ was implemented at $50{ }^{\circ} \mathrm{C}$ for $1 \mathrm{~h}$, followed by physical removal of adsorbed $\mathrm{NO}_{x}$ with $\mathrm{N}_{2}$ for $0.5 \mathrm{~h}$. Finally, the temperature of samples was raised from 50 to $400{ }^{\circ} \mathrm{C}$ with an ascending rate of $10^{\circ} \mathrm{C} \mathrm{min}^{-1}$ under $\mathrm{N}_{2}$ flow. A Thermo Fisher IS10 FTIR was used to record the concentrations of $\mathrm{NO}_{x}$ for the inlet and outlet gases. XPS analysis was carried out on an ESCALab 250 electron spectrometer (Thermo Scientific Corporation) in which the $\mathrm{Al} \mathrm{K} \alpha$ radiation source $(1486.6 \mathrm{eV})$ was adopted at $15 \mathrm{~kW}$ accelerating power. In order to compensate for the charge effect of catalysts, the $\mathrm{C} 1 \mathrm{~s}$ peak of $284.6 \mathrm{eV}$ was used to calibrate all binding energies (BE) of catalysts. The in situ DRIFT spectra were carried out on a Nicolet 6700 instrument produced by the Simefei company and equipped with a liquid nitrogen-cooled MCT detector with $4 \mathrm{~cm}^{-1}$ resolution. Before each measurement, the sample was pre-treated under $\mathrm{N}_{2}$ atmosphere for $30 \mathrm{~min}\left(300^{\circ} \mathrm{C}\right)$ and then cooled to $50{ }^{\circ} \mathrm{C}$ while the background was recorded. Subsequently, $500 \mathrm{ppm} \mathrm{NO}+5 \%$ vol. $\mathrm{O}_{2}$ was introduced into the cell and the DRIFT spectra were recorded. The final spectra were obtained after $\mathrm{NO}+\mathrm{O}_{2}$ co-adsorption for $30 \mathrm{~min}$ and purging with $\mathrm{N}_{2}$ for another $10 \mathrm{~min}$.

\subsection{Catalytic activity test}

The activity testing was performed in fixed-bed reactor. A quartz reactor was filled with $0.3-0.4 \mathrm{~g}$ catalysts (40-60 mesh). A model flue gas (500 ppm $\mathrm{NH}_{3}, 500 \mathrm{ppm} \mathrm{NO}, 5$ vol\% $\mathrm{O}_{2}, 0$ or $100 \mathrm{ppm}$ $\mathrm{SO}_{2}, 0$ or 10 vol\% $\mathrm{H}_{2} \mathrm{O}$, and $\mathrm{N}_{2}$ as equilibrium gas) was used in all experiments. During the process, the flow rate was 187 $\mathrm{cm}^{3} \mathrm{~min}^{-1}$ and the gas hourly space velocity (GHSV) was 45000 $\mathrm{h}^{-1}$. A Thermo Fisher IS10 FTIR was used to record the concentrations of $\mathrm{NO}_{x}$ for the inlet and outlet gases every $10 \mathrm{~min}$ in the temperature range of $90-360{ }^{\circ} \mathrm{C}$.

The $\mathrm{NO}_{x}$ conversion and $\mathrm{N}_{2}$ selectivity were separately calculated basing on the following formulas:

$$
\mathrm{NO}_{x} \text { conversion }(\%)=\left\{\frac{\left[\mathrm{NO}_{x}\right]_{\text {in }}-\left[\mathrm{NO}_{x}\right]_{\text {out }}}{\left[\mathrm{NO}_{x}\right]_{\text {in }}}\right\} \times 100 \%
$$

$\mathrm{N}_{2}$ selectivity (\%)

$$
\begin{aligned}
= & \left\{\frac{\left\{\left[\mathrm{NO}_{x}\right]_{\text {in }}+\left[\mathrm{NH}_{3}\right]_{\text {in }}-\left[\mathrm{NO}_{x}\right]_{\text {out }}-2\left[\mathrm{~N}_{2} \mathrm{O}\right]_{\text {out }}-\left[\mathrm{NH}_{3}\right]_{\text {out }}\right\}}{\left[\mathrm{NO}_{x}\right]_{\text {in }}+\left[\mathrm{NH}_{3}\right]_{\text {in }}-\left[\mathrm{NO}_{x}\right]_{\text {out }}-\left[\mathrm{NH}_{3}\right]_{\text {out }}}\right\} \\
& \times 100 \%
\end{aligned}
$$

where the inlet concentrations of $\mathrm{NO}, \mathrm{NO}_{2}$ and $\mathrm{NH}_{3}$ were labelled $[\mathrm{NO}]_{\mathrm{in}},\left[\mathrm{NO}_{2}\right]_{\mathrm{in}}$ and $\left[\mathrm{NH}_{3}\right]_{\mathrm{in}}$, respectively, and the outlet concentrations of $\mathrm{NO}, \mathrm{NO}_{2}$ and $\mathrm{N}_{2} \mathrm{O}$ were labelled [NO] $]_{\text {out }}$, $\left[\mathrm{NO}_{2}\right]_{\text {out }}$ and $\left[\mathrm{N}_{2} \mathrm{O}\right]_{\text {out }}$, respectively. 


\section{$2.4 \quad$ Kinetic test}

The feed-gas mixture is the same as in the above activity test. In order to eliminate the diffusion effect, experiments were performed with different particle sizes and different flow rates. For the $\mathrm{NH}_{3}$-SCR model reaction, the apparent activation energies $\left(E_{\mathrm{a}}\right)$ for these catalysts were acquired from the following formula:

$$
\ln k=-\frac{E_{\mathrm{a}}}{R T}+\ln A
$$

where the reaction rate constant $\left(\mathrm{cm}^{3} \mathrm{~g}^{-1} \mathrm{~s}^{-1}\right)$, the preexponential factor $\left(\mathrm{cm}^{3} \mathrm{~g}^{-1} \mathrm{~s}^{-1}\right)$, the standard gas constant ( $\mathrm{J}$ $\mathrm{mol}^{-1} \mathrm{~K}^{-1}$ ), and the reaction temperature (K) were respectively labelled as $k, A, R$, and $T$.

The reaction rate constant $(k)$ as a function of NO conversion (\%) can be calculated through the formula below:

$$
k=-\frac{V}{W} \times \ln (1-x)
$$

in which the reaction rate coefficient $\left(\mathrm{cm}^{3} \mathrm{~g}^{-1} \mathrm{~s}^{-1}\right)$, the catalyst weight $(\mathrm{g})$, the volumetric flow rate $\left(\mathrm{cm}^{3} \mathrm{~s}^{-1}\right)$ and the NO conversion (\%) were labelled as $k, W, V$ and $x$, respectively.

\section{Results and discussion}

\subsection{The structure characterization of catalysts}

3.1.1 XRD analysis of pristine LDHs. XRD was used to investigate the crystalline micro-structures of the initial LDH precursors, as displayed in Fig. 1. All the prepared samples displayed distinctive diffraction peaks for the (003) and (006) planes characteristic of hydrotalcites. ${ }^{20}$ It is worth mentioning that the transition metal $(\mathrm{Cu}, \mathrm{Ni}$ or $\mathrm{Co})$ incorporation did cause distinct modification of the precursors in which their FWHM became significantly wider. Considering the Scherrer formula, this conveyed that the three doped precursors possessed relatively smaller crystal sizes. This phenomenon hinted that the transition metal ( $\mathrm{Cu}, \mathrm{Ni}$ or $\mathrm{Co}$ ) doping changed the morphology of LDHs precursors, which should contribute to the

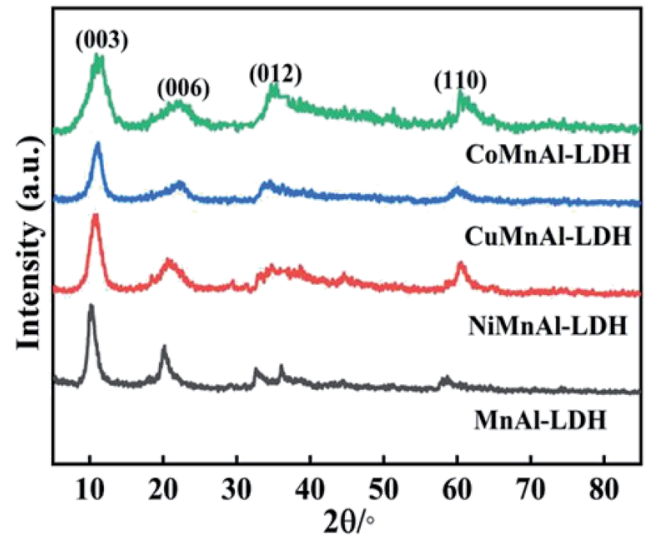

Fig. 1 XRD patterns of MnAl-LDH, CuMnAl-LDH, NiMnAl-LDH and COMnAl-LDH.
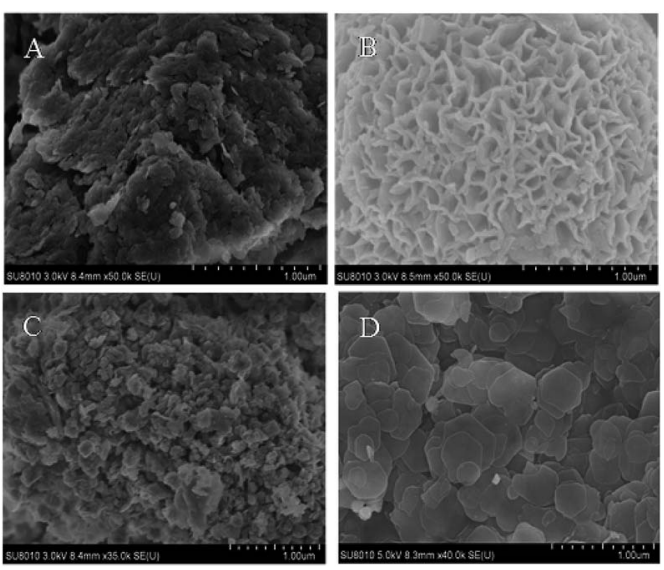

Fig. 2 SEM images of (A) MnAl-LDH, (B) CuMnAl-LDH, (C) NiMnAl$\mathrm{LDH}$ and (D) COMnAl-LDH.

dispersibility of the corresponding calcined products. This also can be certified by SEM and TEM characterization analysis.

3.1.2 SEM analysis. The morphologies of as-prepared LDHs were characterized using SEM. All samples presented brucitelike structure with well-defined platelets, as displayed in Fig. 2.

For unaltered MnAl-LDH, the agglomeration body was especially apparent, although there existed sheets on the surface of catalyst. After introducing the transition metal, the agglomeration was effectively improved. Surprisingly, the CoMnAl-LDH presented very thin and regular hexagonal platelets which were in favour of the gas-solid heterogeneous catalytic reactions. ${ }^{21}$ For NiMnAl-LDH, the nanoplatelets were the same as CoMnAl-LDH, but the stacking was a little disordered. CuMnAl-LDH had similar "flower-like" shapes, consisting of very thick nanoplatelets.

3.1.3 FT-IR. The FT-IR spectra of MMnAl-LDHs are shown in Fig. 3. According to previous literature, the FT-IR spectra of all pristine $\mathrm{LDHs}$ deliver typical adsorption peaks like $\mathrm{Mg}-\mathrm{Al}$ hydrotalcite. ${ }^{22}$ It is clear that there exists a broad peak located at $3450 \mathrm{~cm}^{-1}$, which can be assigned to the stretching vibrations

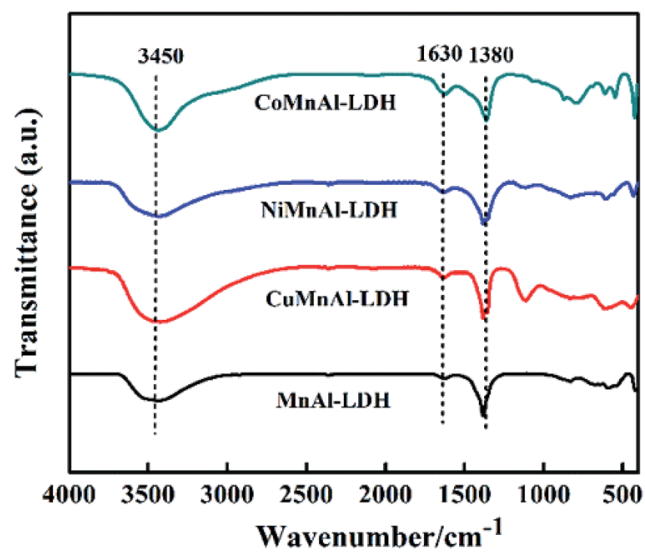

Fig. 3 FT-IR spectra of MnAl-LDH, CuMnAl-LDH, NiMnAl-LDH and COMnAl-LDH. 
of the -OH groups of the brucite-like layers. ${ }^{23}$ All LDHs presented a similar peak located at $1630 \mathrm{~cm}^{-1}$ which can be assigned to the vibration of angular deformation of $\mathrm{H}_{2} \mathrm{O}$ molecules. ${ }^{24}$ The vibrations of $\mathrm{CO}_{3}{ }^{2-}$ are related to the absorption band located at $1380 \mathrm{~cm}^{-1} \cdot{ }^{25,26}$ Finally, the absorption bands in the range of $800-500 \mathrm{~cm}^{-1}$ can be ascribed to the vibrations of $\mathrm{M}-\mathrm{O}$ from $\mathrm{M}-\mathrm{OH}, \mathrm{O}-\mathrm{M}-\mathrm{O}$, or $\mathrm{M}-\mathrm{O}-\mathrm{M}$ in the hydrotalcite structure. ${ }^{23-25}$ These data further suggest that $\mathrm{LDH}$ precursors were successfully synthesized.

\subsection{SCR performance of the MMnAl mixed oxide catalysts}

3.2.1 SCR activity. The Co-, Ni- or Cu-modified MnAl-LDO catalysts were obtained via calcination treatment at $500{ }^{\circ} \mathrm{C}$ to avoid the influence of residual organic fractions. The respective results of SCR activity and $\mathrm{N}_{2}$ selectivity of MnAl-LDO, CoMnAlLDO, NiMnAl-LDO and CuMnAl-LDO catalysts are presented in Fig. 4(A) and (B). It is worth mentioning that the different doping transition elements $(\mathrm{Co}, \mathrm{Ni}, \mathrm{Cu})$ in the $\mathrm{MnAl}$ mixed oxides significantly influenced the catalytic performance. Notably, although the activity over the Ni-doped MnAl-LDO had a slight improvement in the low temperature region $\left(<250{ }^{\circ} \mathrm{C}\right)$, the activity over Co-doped catalyst sharply rose, achieving $81 \%$ conversion of $\mathrm{NO}$ at $150{ }^{\circ} \mathrm{C}$ and above $95 \%$ conversion in the
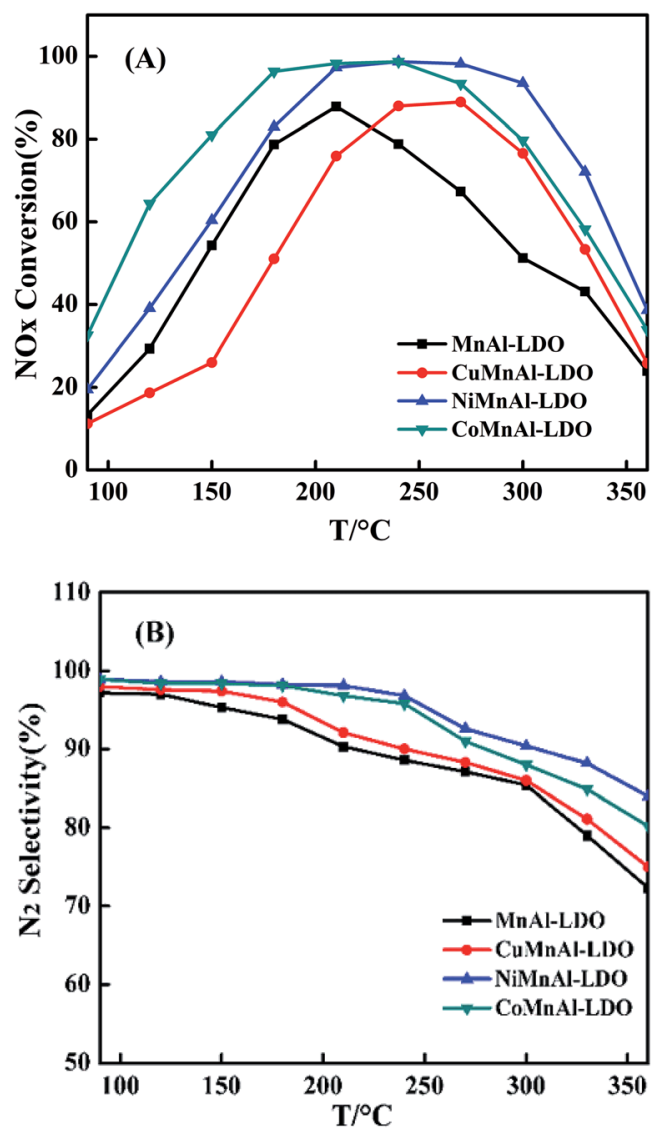

Fig. 4 (A) $\mathrm{NO}_{x}$ conversion and (B) $\mathrm{N}_{2}$ selectivity of MnAl-LDO, CuMnAl-LDO, NiMnAl-LDO and CoMnAl-LDO. range of $180{ }^{\circ} \mathrm{C}$ to $240{ }^{\circ} \mathrm{C}$, much higher than the activity of the MnAl-LDO catalyst. However, another phenomenon can be observed during the process. After introduction of $\mathrm{Cu}$ into MnAl-LDO, the low-temperature activity $\left(<250{ }^{\circ} \mathrm{C}\right)$ considerably decreased. Moreover, upon further increase of the temperature $\left(>250{ }^{\circ} \mathrm{C}\right)$, the catalytic activity decreased dramatically for all catalysts. Fig. 4(B) shows the $\mathrm{N}_{2}$ selectivity over all catalysts. Note that the $\mathrm{MnAl}$ catalyst presented worse $\mathrm{N}_{2}$ selectivity than the $\mathrm{Cu}^{-}, \mathrm{Co}^{-}$, and $\mathrm{Ni}$-doped catalysts in which the transition metals significantly enhanced the $\mathrm{N}_{2}$ selectivity. As can be seen from the diagram, the sequence of transition metal enhancement of $\mathrm{N}_{2}$ selectivity in the $\mathrm{NH}_{3}$-SCR reaction system was ranked as follows: $\mathrm{Ni}>\mathrm{Co}>\mathrm{Cu}$.

\subsection{Structure-property correlation}

3.3.1 XRD analysis of MMnAl mixed metal oxides. In Fig. 5, the XRD result displays the crystal phases of the MnAl-LDO, CuMnAl-LDO, NiMnAl-LDO, CoMnAl-LDO catalysts calcined at $500{ }^{\circ} \mathrm{C}$. For MnAl-LDO samples, the diffraction pattern showed peaks at $18.1^{\circ}, 28.9^{\circ}, 30.7^{\circ}, 32.5^{\circ}$, and $36.1^{\circ}$, corresponding to $\mathrm{Mn}_{3} \mathrm{O}_{4} \cdot{ }^{27}$ Meanwhile, the characteristic peaks assigned to $\mathrm{CuO}$, $\mathrm{NiO}$ and $\mathrm{Co}_{3} \mathrm{O}_{4}$ were clearly observed in the respective CuMnAlLDO, NiMnAl-LDO and CoMnAl-LDO catalysts. ${ }^{21,28,29}$ In addition, except for the MnAl-LDO, there is no noticeable diffraction peak for $\mathrm{MnO}_{x}$ observed in the XRD patterns of the $\mathrm{Cu}-, \mathrm{Co}-$ and $\mathrm{Ni}$-doped catalysts, indicating the good dispersion of $\mathrm{MnO}_{x}$ on the catalyst surface.

3.3.2 BET analysis. For all catalysts, the $\mathrm{N}_{2}$ adsorptiondesorption isotherms are shown in Fig. 6. The isotherms presented a typical type IV isotherm accompanied by a type $\mathrm{H}_{2}$ hysteresis loop, indicating capillary condensation occurring in a definite mesoporous structure. ${ }^{30}$ It is clear that different doping transition metals affected the specific surface area to some degree, which may be related to the different calcined products from LDH precursors. ${ }^{8}$ From this diagram, it can be found that the specific surface area of CuMnAl-LDO was slightly improved. In addition, the NiMnAl-LDO and CoMnAl-LDO catalysts were found to have higher surface areas relative to

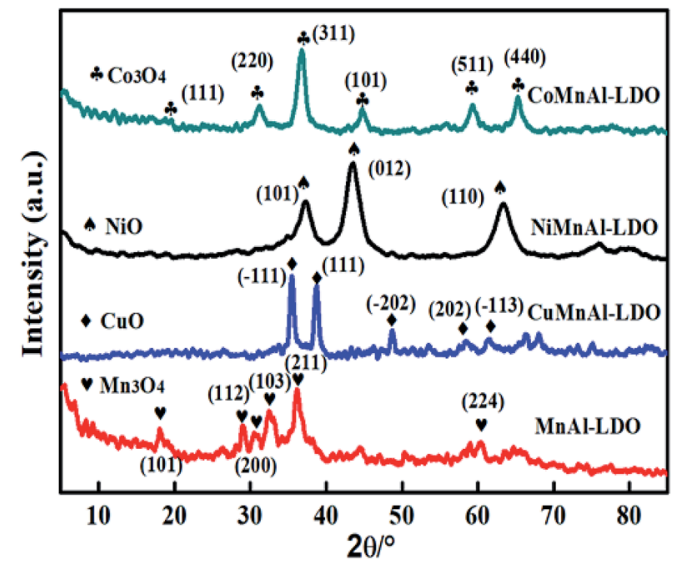

Fig. 5 The XRD patterns of MnAl-LDO, CuMnAl-LDO, NiMnAl-LDO and CoMnAl-LDO. 


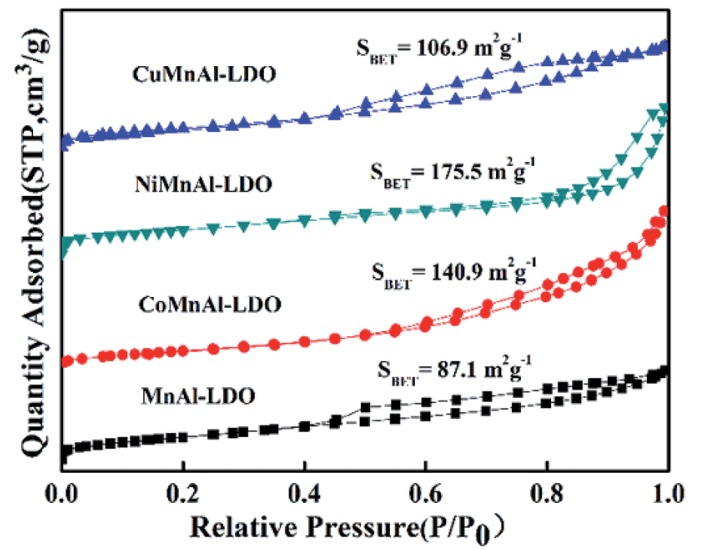

Fig. 6 The $\mathrm{N}_{2}$ adsorption-desorption isotherms of MnAl-LDO, CuMnAl-LDO, NiMnAl-LDO and COMnAl-LDO.

the MnAl-LDO and CuMnAl-LDO catalysts, and the two former possessed higher $\operatorname{DeNO}_{x}$ activity. The result suggests that the higher surface areas are in favour of $\mathrm{DeNO}_{x}$ activity because they
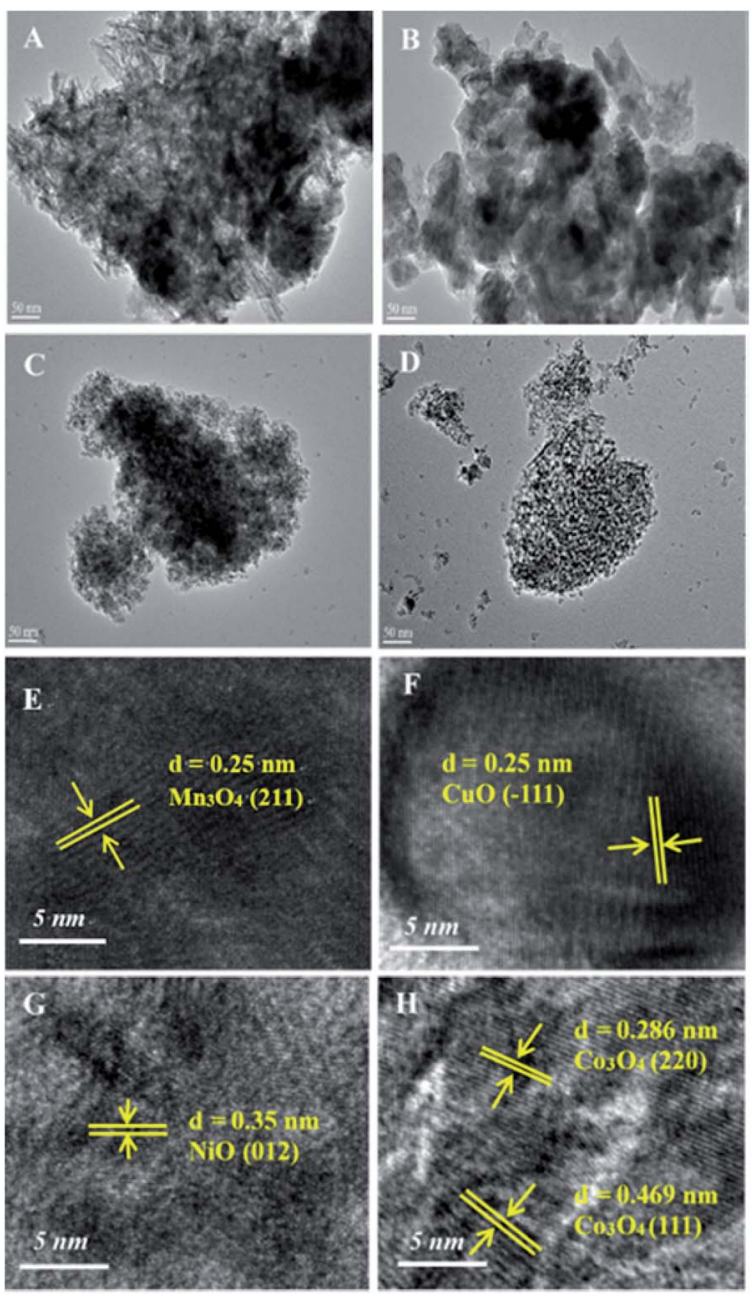

Fig. 7 TEM images of (A and E) MnAl-LDO, (B and F) CuMnAl-LDO, (C and $\mathrm{G}) \mathrm{NiMnAl-LDO}$ and (D and H) CoMnAl-LDO. can offer more active sites for reactants. ${ }^{31,32}$ An interesting phenomenon was discovered, in that NiMnAl-LDO displayed the largest specific surface area among all the catalysts while showing inferior catalytic performance to CoMnAl-LDO, hinting that the specific surface area is not the single influencing factor.

3.3.3 TEM analysis. The TEM analysis further disclosed the microstructures of the different mixed oxides, as shown in Fig. 7. For MnAl-LDO, the particles were clearly nonuniform in size and distribution and displayed apparent agglomeration. After introducing $\mathrm{Cu}$, the above shortcomings were not much improved. Inspiringly, the nanoparticles were very uniformly distributed over the surface of CoMnAl-LDO and NiMnAl-LDO catalysts in comparison to the other two catalysts. For the MnAl-LDO catalyst, the obvious (211) crystal plane of $\mathrm{Mn}_{3} \mathrm{O}_{4}$ can be referenced to the lattice fringe of $0.25 \mathrm{~nm} .^{33}$ The $(-111)$ crystal plane of $\mathrm{CuO}$ and (012) crystal plane of $\mathrm{NiO}$ are found in Fig. 7(E) and (F) with lattice fringes of $0.25 \mathrm{~nm}$ and $0.35 \mathrm{~nm},{ }^{21,34}$ respectively. The lattice fringes with interplanar distances of $0.28 \mathrm{~nm}$ and $0.46 \mathrm{~nm}$ can be respectively ascribed to the (220) and (111) planes of $\mathrm{Co}_{3} \mathrm{O}_{4} \cdot{ }^{35}$ These results further confirm the XRD results.

3.3.4 XPS analysis. In order to make clear the underlying causes, XPS spectra were acquired for MnAl-LDO and $\mathrm{Cu}^{-}, \mathrm{Ni}-$, and Co-doped catalysts calcined at $500{ }^{\circ} \mathrm{C}$, as illustrated in Fig. 8, with the relative concentration ratios summarized in Table 1. The XPS spectra of Mn 2p for all samples are shown in Fig. 8(A). After completing peak-fitting deconvolution for $\mathrm{Mn}$ $2 \mathrm{p}_{3 / 2}$, three distinct peaks at $642.0,643.2$, and $645.0 \mathrm{eV}$ were observed, which can be correspondingly attributed to $\mathrm{Mn}^{3+}$, $\mathrm{Mn}^{4+}$ and a satellite peak. Apparently, the amount of surface $\mathrm{Mn}^{4+}$ over the MnAl-LDO catalyst was higher compared with the other catalysts, which can result in excessive $\mathrm{NH}_{3}$ oxidation at higher temperatures. Therefore, the MnAl-LDO catalyst afforded poor $\mathrm{N}_{2}$ selectivity, as shown in Fig. 4(B). However, the Co and $\mathrm{Ni}$ additions endowed the CoMnAl-LDO and NiMnAl-LDO catalysts with reasonable oxidation through the full operating temperature range, which can give rise to not only improved low-temperature activity but also enhanced $\mathrm{N}_{2}$ selectivity. Additionally, the $\mathrm{Mn} 2 \mathrm{p}_{3 / 2}$ peaks of the M-MnAl-LDO $(\mathrm{M}=\mathrm{Cu}$, $\mathrm{Co}, \mathrm{Ni}$ ) catalysts presented a minor shift toward lower binding energy compared to MnAl-LDO, indicating the existence of a strong interaction between $\mathrm{MnO}_{x}$ and $\mathrm{MO}_{x}$, which would further make electron transfer more convenient.

Fig. 8(B) shows the XPS spectra of $\mathrm{O} 1 \mathrm{~s}$, which can be fitted into two characteristic peaks at $530.1 \mathrm{eV}$ and $531.7 \mathrm{eV}$ respectively belonging to lattice oxygen and chemisorbed oxygen, hereafter termed $\mathrm{O}_{\beta}$ and $\mathrm{O}_{\alpha}$. From Table 1 , it can be clearly observed that the $\mathrm{O}_{\alpha} / \mathrm{O}_{\beta}$ ratio on the surface of the CoMnAl-LDO catalyst was higher than those of the other catalysts. The $\mathrm{O}_{\alpha}$, with higher mobility, is more conductive to oxidation reactions, ${ }^{36}$ which can enhance the DeNO $_{x}$ activity of CoMnAl-LDO catalyst to some extent. Further XPS data processing revealed that $\mathrm{Co}^{3+} / \mathrm{Co}^{2+}, \mathrm{Ni}^{3+} / \mathrm{Ni}^{2+}$ and $\mathrm{Cu}^{2+} / \mathrm{Cu}^{+}$exist in the separate systems of CoMnAl-LDO, NiMnAl-LDO, CuMnAl-LDO. In general, more $\mathrm{Co}^{3+}, \mathrm{Ni}^{3+}$ and $\mathrm{Cu}^{2+}$ species were preferable for redox ability, while the existence of redox circles like $\mathrm{Co}^{3+}+$ $\mathrm{Mn}^{3+} \leftrightarrow \mathrm{Co}^{2+}+\mathrm{Mn}^{4+}, \mathrm{Ni}^{3+}+\mathrm{Mn}^{3+} \leftrightarrow \mathrm{Ni}^{2+}+\mathrm{Mn}^{4+}$ and $\mathrm{Cu}^{2+}+$ 

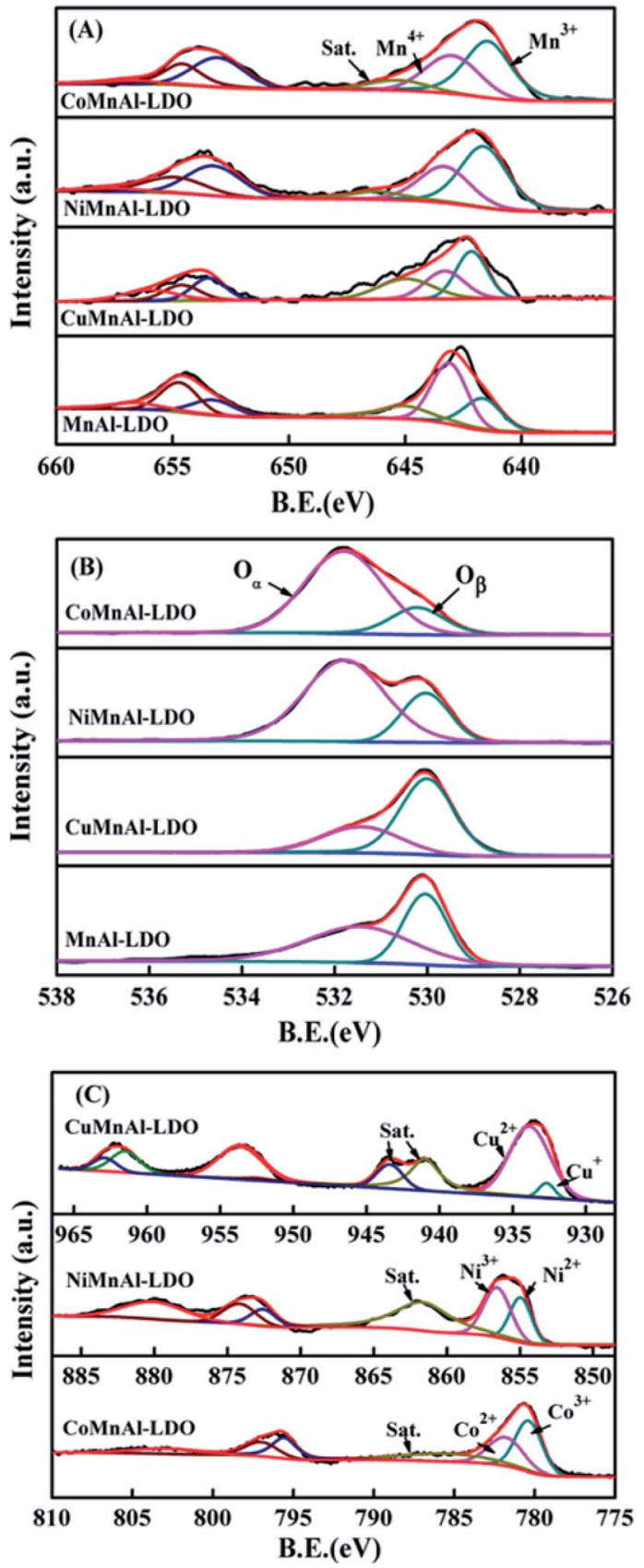

Fig. 8 XPS results of (A) Mn 2p, (B) O 1s, and (C) Cu 2p, Ni 2p, and Co $2 p$ for MnAl-LDO, CuMnAl-LDO, NiMnAl-LDO and COMnAl-LDO.

$\mathrm{Mn}^{3+} \leftrightarrow \mathrm{Cu}^{+}+\mathrm{Mn}^{4+}$ also played a major role in improving the catalytic activity. ${ }^{37,38}$

3.3.5 $\quad \mathrm{H}_{2}$-TPR analysis. The $\mathrm{H}_{2}$-TPR technique was used to evaluate the surface redox behavior of the catalysts and the $\mathrm{H}_{2}$ TPR profiles are shown in Fig. 9. For the pure MnAl-LDO catalyst, two reduction peaks observed at roughly 324 and $502{ }^{\circ} \mathrm{C}$ were assigned to the continuous reduction of $\mathrm{MnO}_{2} / \mathrm{Mn}_{2} \mathrm{O}_{3} /$ $\mathrm{Mn}_{3} \mathrm{O}_{4} \rightarrow \mathrm{MnO}^{27}$ The TPR curve of CuMnAl-LDO catalyst shows a reduction peak at $284^{\circ} \mathrm{C}$ which can be ascribed to the stepwise reduction of $\mathrm{CuO}$, along with the reduction of $\mathrm{MnO}_{x} \cdot{ }^{39}$ With regard to CoMnAl-LDO, there was a broad medium-temperature
Table 1 Surface oxidation states calculated from XPS

\begin{tabular}{|c|c|c|c|c|c|}
\hline & $\operatorname{Mn} 2 p$ & O 1s & $\mathrm{Cu} 2 \mathrm{p}$ & Ni $2 p$ & Co $2 p$ \\
\hline Catalysts & $\mathrm{Mn}^{4+} / \mathrm{Mn}^{3+}$ & $\mathrm{O}_{\alpha} / \mathrm{O}_{\beta}$ & $\mathrm{Cu}^{2+} / \mathrm{Cu}^{+}$ & $\mathrm{Ni}^{3+} / \mathrm{Ni}^{2+}$ & $\mathrm{Co}^{3+} / \mathrm{Co}^{2+}$ \\
\hline MnAl-LDO & 1.66 & 1.10 & - & - & - \\
\hline CuMnAl-LDO & 0.62 & 0.68 & 12.04 & - & - \\
\hline NiMnAl-LDO & 0.67 & 2.77 & - & 1.38 & - \\
\hline CoMnAl-LDO & 0.75 & 3.70 & - & - & 1.47 \\
\hline
\end{tabular}

peak in the temperature range of $300-400{ }^{\circ} \mathrm{C}$ in which $\mathrm{Co}_{3} \mathrm{O}_{4}$ and $\mathrm{MnO}_{x}$ were gradually reduced. Additionally, the peak in the high-temperature region $\left(500-900{ }^{\circ} \mathrm{C}\right)$ could be assigned to the reduction of $\mathrm{CoO}$ or cobalt aluminates..$^{40}$ For NiMnAl-LDO catalyst, the reduction peak located at $489^{\circ} \mathrm{C}$ corresponded to the reduction of $\mathrm{Ni}^{3+} / \mathrm{Ni}^{2+}$ to $\mathrm{NiO}$ coupled with the reduction of amorphous $\mathrm{MnO}_{x}{ }^{41}$ This result indicates that doping transition metals can change the redox ability of the MnAl-LDO catalyst. Among these metals, a more suitable interaction between $\mathrm{CuO}_{x}$ species and $\mathrm{MnO}_{x}$ may be responsible for the lower reducing temperature. As the number of reducible species on the surface of catalyst is also an important factor affecting the $\mathrm{DeNO}_{x}$ activity, the hydrogen consumption for each catalyst was calculated and is shown in Table 2. Obviously, the CoMnAl-LDO $\left(10.1 \mathrm{mmol} \mathrm{g}^{-1}\right)$ and NiMnAl-LDO $\left(11.3 \mathrm{mmol} \mathrm{g}^{-1}\right)$ catalysts consumed more hydrogen than MnAl-LDO $\left(6.4 \mathrm{mmol} \mathrm{g}^{-1}\right.$ ), indicating there were more reducible species over the surfaces of CoMnAl-LDO and NiMnAl-LDO which provide more redox sites and enable sufficient redox reactions. For the CuMnAlLDO catalyst, the presence of a reduction peak at lower temperature can be an indication of its good reducibility. However, the limited redox sites (hydrogen consumption: $2.6 \mathrm{mmol} \mathrm{g}^{-1}$ ) are a disadvantage which might account for its lower catalytic activity. The above results are, to some extent, in accordance with the catalytic performances of the catalysts.

3.3.6 $\mathrm{NH}_{3}$-TPD analysis. $\mathrm{NH}_{3}$-TPD measurements were used to study the number and strength of the acid sites over the

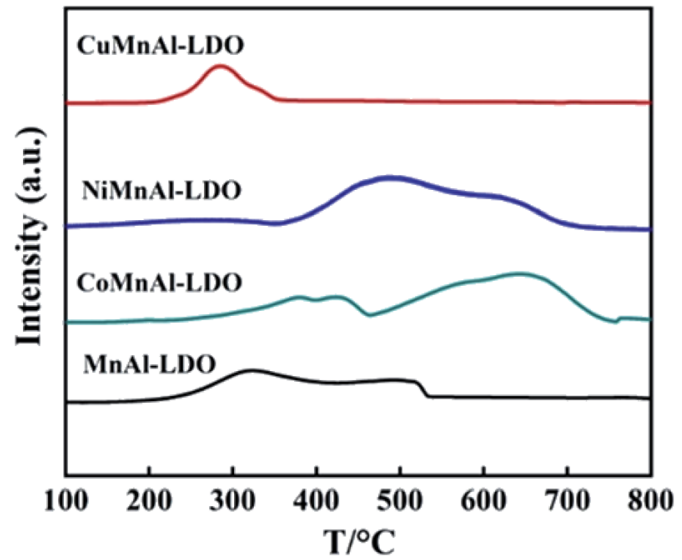

Fig. $9 \mathrm{H}_{2}$-TPR results of MnAl-LDO, CuMnAl-LDO, NiMnAl-LDO and COMnAl-LDO 
Table $2 \mathrm{H}_{2}$ consumption and $\mathrm{NO}_{x}$ desorption of the four catalysts

\begin{tabular}{|c|c|c|c|c|c|c|c|}
\hline \multirow[b]{2}{*}{ Catalyst } & \multicolumn{2}{|c|}{$\begin{array}{l}\text { Reduction } \\
\text { temperature } \\
\left({ }^{\circ} \mathrm{C}\right) \\
\end{array}$} & \multirow[b]{2}{*}{$\begin{array}{l}\mathrm{H}_{2} \text { consumption } \\
\left(\mathrm{mmol} \mathrm{g}^{-1}\right)\end{array}$} & \multicolumn{3}{|c|}{$\mathrm{NO}_{x}$ desorption (\%) } & \multirow[b]{2}{*}{$\begin{array}{l}\text { Total } \mathrm{NO}_{x} \text { desorption } \\
\text { (a.u.) }\end{array}$} \\
\hline & $T_{1}$ & $T_{2}$ & & $\begin{array}{l}100-150 \\
{ }^{\circ} \mathrm{C}\end{array}$ & $\begin{array}{l}150-200 \\
{ }^{\circ} \mathrm{C}\end{array}$ & $>200{ }^{\circ} \mathrm{C}$ & \\
\hline CoMnAl-LDO & 395 & 646 & 10.1 & 38.9 & 31.7 & 29.4 & 2.5 \\
\hline NiMnAl-LDO & 489 & - & 11.3 & 59.5 & 40.5 & - & 1.1 \\
\hline CuMnAl-LDO & 284 & - & 2.6 & - & 42.9 & 57.1 & 1.3 \\
\hline MnAl-LDO & 324 & 502 & 6.4 & - & 56.3 & 43.7 & 1 \\
\hline
\end{tabular}

surface of the catalysts. As is well known, surface acidity is in favour of $\mathrm{NH}_{3}$ adsorption, which is an essential step for the reaction in the $\mathrm{NH}_{3}$-SCR system. ${ }^{42}$ The $\mathrm{NH}_{3}$-TPD profiles for all the catalysts are depicted in Fig. 10. The MnAl-LDO catalyst presented a small desorption peak at $143{ }^{\circ} \mathrm{C}$ belonging to the weak acid sites $\left(<200{ }^{\circ} \mathrm{C}\right)$ and a large desorption peak at $303{ }^{\circ} \mathrm{C}$ belonging to the medium acid sites $\left(200-450^{\circ} \mathrm{C}\right)$. In contrast to MnAl-LDO catalyst, the weak acid sites of all transition-metaldoped catalysts increased significantly, suggesting that the addition of transition metals afforded more weak acid sites. Notably, although the weak acid sites of CuMnAl-LDO were improved, its ability for $\mathrm{NO}_{x}$ adsorption was weak, as confirmed in the $\mathrm{NO}+\mathrm{O}_{2}$-TPD analysis. The poor activity of CuMnAl in the low-temperature region can be further explained. It can also be seen that the strong acid sites, to a different extent, depend on the identity of the transition metal. Both NiMnAl-LDO and CoMnAl-LDO catalysts have a broad $\mathrm{NH}_{3}$ desorption peak above $400{ }^{\circ} \mathrm{C}$, which can be attributed to continuous $\mathrm{NH}_{3}$ desorption on medium strong acid sites, while there were no strong acid sites on the surface of CuMnAl-LDO catalyst. These results demonstrated that strong acid sites were beneficial to $\mathrm{NH}_{3}$ adsorption, proportional to the wide temperature windows of NiMnAl-LDO and CoMnAl-LDO catalysts.

3.3.7 NO $+\mathbf{O}_{2}$-TPD analysis. As with the acid sites, the catalysts' adsorption behavior of the other major reactant $\left(\mathrm{NO}_{x}\right)$

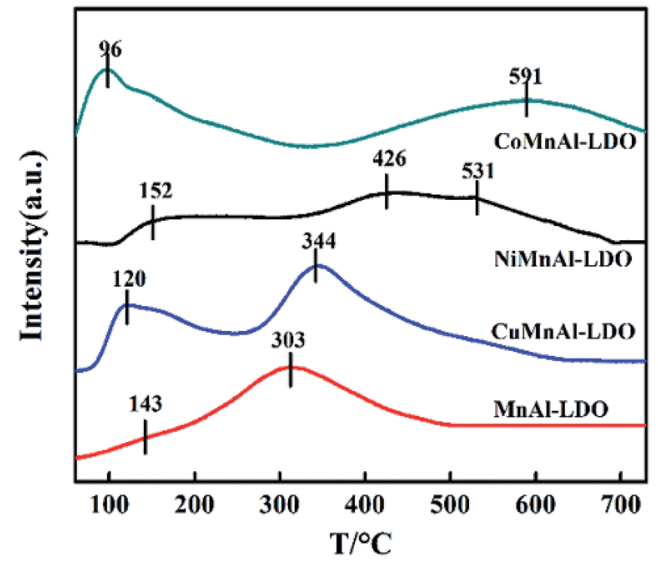

Fig. $10 \mathrm{NH}_{3}-$ TPD results of MnAl-LDO, CuMnAl-LDO, NiMnAl-LDO and COMnAl-LDO. and its further activation also play an important role in the SCR reaction. Hence, $\mathrm{NO}+\mathrm{O}_{2}$-TPD for each catalyst was investigated and the results are shown in Fig. 11, with the in situ DRIFT spectra of $\mathrm{NO}+\mathrm{O}_{2}$ co-adsorption displayed in Fig. 12. The MnAlLDO catalyst exhibits two desorption peaks located at 188 and $350{ }^{\circ} \mathrm{C}$. After $\mathrm{Cu}$ modification, the number of $\mathrm{NO}_{x}$ adsorption sites slightly increased from 1 to 1.3 in CuMnAl-LDO, as shown in Table 2. However, it can be seen that the intensity of the desorption peak at low temperature $\left(197^{\circ} \mathrm{C}\right)$ decreased, while that of the high temperature desorption peak $\left(352{ }^{\circ} \mathrm{C}\right)$ increased, implying the formation of more stable (normally more inactive) adsorbed $\mathrm{NO}_{x}$ species. This result can explain to a certain degree the inferior low temperature $\mathrm{DeNO}_{x}$ activity of the CuMnAl-LDO catalyst. For the CoMnAl-LDO and NiMnAlLDO catalysts, the desorption peaks were shifted to lower temperature region, indicating the $\mathrm{Co}$ - or Ni-doping can remarkably reduce the stability of the adsorbed $\mathrm{NO}_{x}$ species, which is more likely to provide reactive intermediates. Meanwhile, as can be seen in Table 2, doping with Co and Ni caused a new desorption peak below $150^{\circ} \mathrm{C}$, in which CoMnAl-LDO has a larger total desorption amount of $\mathrm{NO}_{x}$ than NiMnAl-LDO. These characteristics of CoMnAl-LDO could be associated with its superior low temperature $\mathrm{DeNO}_{x}$ activity.

3.3.8 In situ DRIFT spectra. From the in situ DRIFT spectra (Fig. 12), the IR bands between $1620-1800 \mathrm{~cm}^{-1}$ can be ascribed

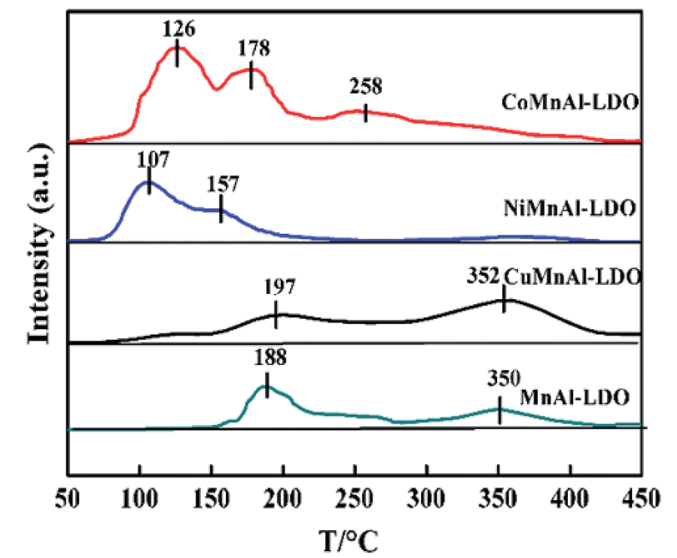

Fig. $11 \mathrm{NO}+\mathrm{O}_{2}$-TPD results of MnAl-LDO, CuMnAl-LDO, NiMnAlLDO and COMnAl-LDO. 


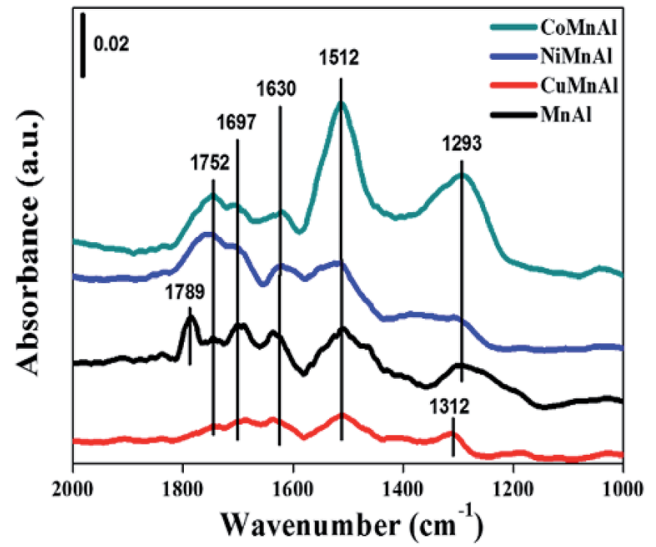

Fig. 12 In situ DRIFT spectra of $\mathrm{NO}+\mathrm{O}_{2} \mathrm{CO}$-adsorption at $50{ }^{\circ} \mathrm{C}$ over MnAl-LDO, CuMnAl-LDO, NiMnAl-LDO and CoMnAl-LDO catalysts.

to physisorbed $\mathrm{N}_{x} \mathrm{O}_{\mathrm{y}}$ molecules, ${ }^{43}$ corresponding to the desorption peaks below $150{ }^{\circ} \mathrm{C}$ in Fig. 11 . Generally speaking, weakly adsorbed $\mathrm{NO}_{x}$ species can be easily activated to participate in the $\mathrm{NH}_{3}$-SCR reaction and are beneficial to the improvement of DeNO $_{x}$ performance at low temperatures. In addition, the bands located at around $1512 \mathrm{~cm}^{-1}$ can be assigned to monodentate nitrate with relatively higher stability and can be related to the desorption peak between $150-200^{\circ} \mathrm{C}$. The desorption peaks at higher temperatures $\left(>200^{\circ} \mathrm{C}\right)$ can be attributed to more stable bidentate or bridged species, which are normally not as active as the monodentate species. ${ }^{44}$ In summary, doping transition metals $(\mathrm{Cu}, \mathrm{Ni}, \mathrm{Co})$ can affect the state of adsorption sites for $\mathrm{NO}_{x}$ on the surface of MnAl-LDO catalysts to some extent. In comparison to CuMnAl-LDO and MnAl-LDO catalysts, CoMnAlLDO and NiMnAl-LDO catalysts presented better low temperature catalytic activity based on their suitable $\mathrm{NO}_{x}$ adsorption.

\subsection{Kinetic analysis}

3.4.1 Apparent activation energy. The calculation of apparent activation energy $\left(E_{\mathrm{a}}\right)$ can provide a valuable reference for evaluating the different catalytic activities. In the conventional $\mathrm{NH}_{3}$-SCR reaction, the concentration of $\mathrm{O}_{2}$ in the reactants is greatly excessive and $\mathrm{NH}_{3}$ has a strong adsorption capacity. Thus, it is usually regarded as a quasi-first-order reaction (the reaction rate is first-order with respect to NO and zero-order with respect to $\mathrm{NH}_{3}$ ) for kinetic evaluation. ${ }^{45-49}$ Although this assumption may be imperfect, it can still provide a relatively valuable reference as a general way of calculating $E_{\mathrm{a}}$ in this study and the relevant formula for $E_{\mathrm{a}}$ has been presented in Section 2.4. It should be pointed out that the influences of internal and external diffusion have been excluded before calculating the apparent activation energy; corresponding experimental data are exhibited in Table S1, Fig. S1 and S2. $\dagger$ Fig. 13 shows the activation energy curves of the four catalysts at 90-210 ${ }^{\circ} \mathrm{C}$; the $E_{\mathrm{a}}$ for MnAl-LDO, CuMnAl-LDO, NiMnAl-LDO, and CoMnAl-LDO were about $94.5 \mathrm{~kJ} \mathrm{~mol}^{-1}, 91.0 \mathrm{~kJ} \mathrm{~mol}^{-1}$, $50.1 \mathrm{~kJ} \mathrm{~mol}^{-1}$, and $45.8 \mathrm{~kJ} \mathrm{~mol}^{-1}$, respectively. The results suggest that the removal of NO was accessible for NiMnAl-LDO

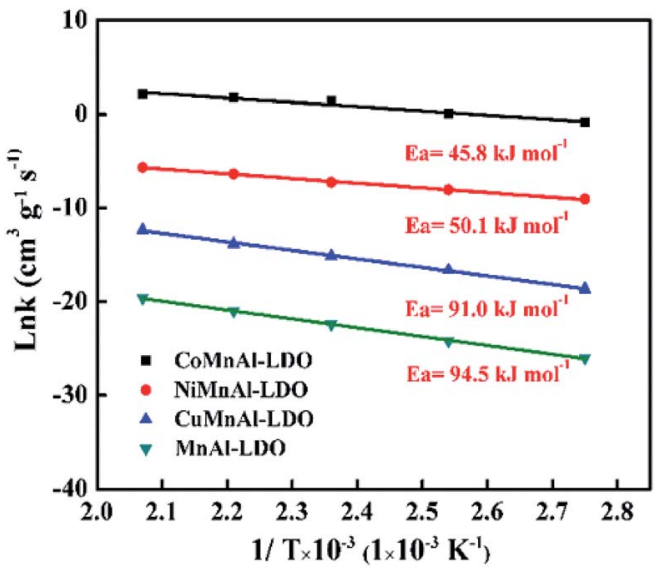

Fig. 13 Arrhenius plots of SCR reaction rates over MnAl-LDO, CuMnAl-LDO, NiMnAl-LDO and COMnAl-LDO.

and CoMnAl-LDO and difficult for MnAl-LDO and CuMnAl-LDO catalysts, in agreement with the results of $\mathrm{DeNO}_{x}$ activity. This result also indicates that the doping of MnAl-LDO by a transition metal $(\mathrm{Co}, \mathrm{Ni}, \mathrm{Cu})$ can influence the activation energy of the reaction process to a certain extent, thereby promoting or inhibiting the $\mathrm{NH}_{3}$-SCR reaction.

\subsection{Stability test and $\mathrm{H}_{2} \mathrm{O} / \mathrm{SO}_{2}$ resistance test}

3.5.1 Stability test. To measure the duration of $\mathrm{DeNO}_{x}$ activity for all the catalysts, a stability experiment was performed at $240{ }^{\circ} \mathrm{C}$ for $60 \mathrm{~h}$ under the same flue gas concentration adopted above, as shown in Fig. 14. After the test, the fluctuation value of $\mathrm{DeNO}_{x}$ activity was $3.2 \%$ for the CoMnAl-LDO, which is slightly lower than that for NiMnAl-LDO (4\%). For the CuMnAl-LDO and NiMnAl-LDO catalysts, the fluctuation values for the $\mathrm{DeNO}_{x}$ activity were approximately $80 \%$, much higher than that of CoMnAl-LDO. It is evident that the CoMnAlLDO possesses a better stability.

3.5.2 $\mathrm{H}_{2} \mathrm{O} / \mathrm{SO}_{2}$ resistance test. In practical use, residual fractions of $\mathrm{SO}_{2}$ and $\mathrm{H}_{2} \mathrm{O}$ will have some unpleasant side effects

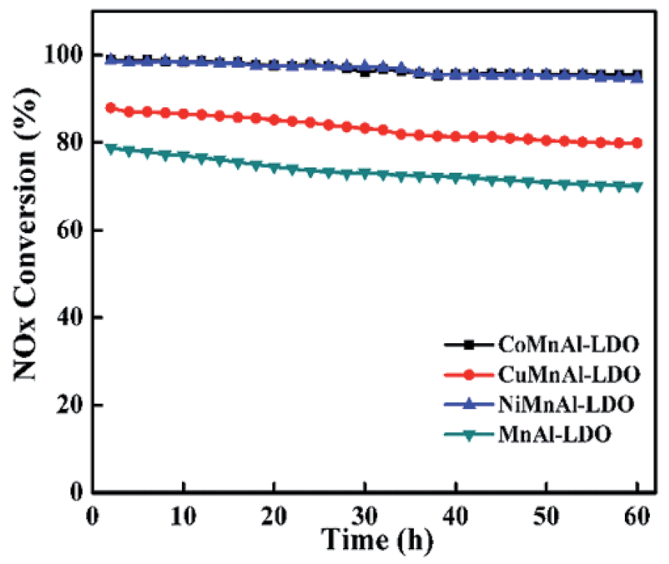

Fig. 14 The results of stability tests over MnAl-LDO, CuMnAl-LDO, NiMnAl-LDO and CoMnAl-LDO. 


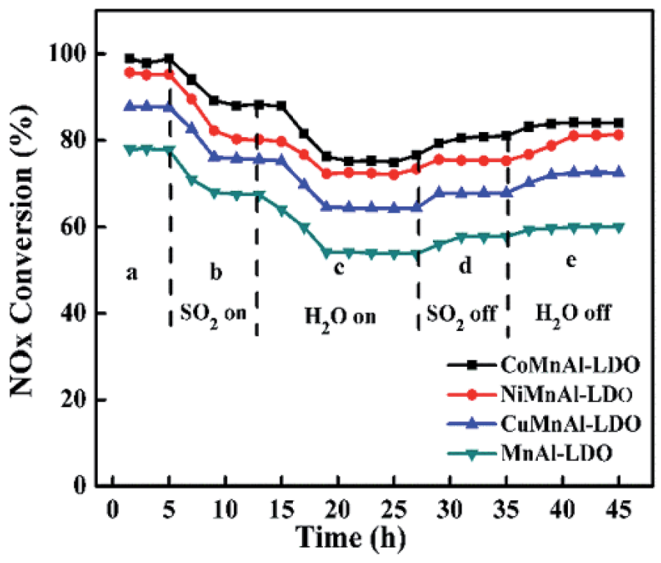

Fig. 15 The results of $\mathrm{SO}_{2} / \mathrm{H}_{2} \mathrm{O}$ durability over MnAl-LDO, CuMnAlLDO, NiMnAl-LDO and COMnAl-LDO.

on the elimination of $\mathrm{NO}_{x}$ for all the catalysts. Therefore, the $\mathrm{SO}_{2} / \mathrm{H}_{2} \mathrm{O}$ durability as a function of time for all catalysts was tested in the $\mathrm{NH}_{3}$-SCR reaction at $240{ }^{\circ} \mathrm{C}$, as shown in Fig. 15 . Initially, the $\mathrm{NO}_{x}$ conversions were at $98.7 \%, 98.7 \%, 88.0 \%$, and $78.8 \%$ for CoMnAl-LDO, NiMnAl-LDO, CuMnAl-LDO, and MnAlLDO, respectively. When $\mathrm{SO}_{2}$ was forced into the reaction system, all catalysts possessed lower $\mathrm{DeNO}_{x}$ activity, declining to $88.3 \%, 80.2 \%, 75.6 \%$, and $67.4 \%$ for CoMnAl-LDO, NiMnAlLDO, CuMnAl-LDO, and MnAl-LDO, respectively. When both $\mathrm{SO}_{2}$ and $\mathrm{H}_{2} \mathrm{O}$ were inleted to the reaction system, a dramatic decrease occurred for all catalysts, especially for CuMnAl-LDO and MnAl-LDO with deceases as high as $23 \%$ and $25 \%$. This suggests that there existed a synergistic inhibition effect on the $\mathrm{NH}_{3}$-SCR reaction process due to the coexistence of $\mathrm{SO}_{2}$ and $\mathrm{H}_{2} \mathrm{O}$. Previous reports have proved that the phenomenon is a result of the formation of sulfate particles that block pores and cover the catalyst surface. ${ }^{50}$ When $\mathrm{SO}_{2}$ was cut off, there were varied recoveries of DeNO ${ }_{x}$ activity. When the supplies of both $\mathrm{SO}_{2}$ and $\mathrm{H}_{2} \mathrm{O}$ were closed, it was observed that the $\mathrm{DeNO}_{x}$ abilities of CoMnAl-LDO and NiMnAl-LDO catalysts were restored to about $84 \%$ and $81.3 \%$, while the $\mathrm{DeNO}_{x}$ abilities for MnAl-LDO and CuMnAl-LDO were only restored to $60.1 \%$ and $72.5 \%$, respectively. Thus, it can be deduced that the CoMnAlLDO catalyst displayed excellent $\mathrm{SO}_{2}$ and $\mathrm{H}_{2} \mathrm{O}$ tolerance.

\section{Conclusions}

In this study, a series of transition metal $(\mathrm{Cu}, \mathrm{Ni}, \mathrm{Co})$ modified $\mathrm{MnAl}$ catalysts were obtained via calcining the corresponding LDH precursors and evaluated for the $\mathrm{NH}_{3}$-SCR reaction. The obtained information suggested that the catalytic activities of the catalysts were strongly dependent on the identity of their transition metal, for which the $\mathrm{NH}_{3}$-SCR reactivity order was CoMnAl-LDO > NiMnAl-LDO > CuMnAl-LDO. The fine catalytic performance in the broadest working temperature window over the CoMnAl-LDO catalyst should be attributed to its good dispersion of active species over the CoMnAl-LDO surface, which could contribute to its optimum redox behavior, plentiful acid sites and $\mathrm{NO}_{x}$ adsorption sites. These findings might open the future potential for LDHs and provide a new mentality for heterogeneous catalysis.

\section{Conflicts of interest}

There are no conflicts of interest to declare.

\section{Acknowledgements}

The project was supported by National Natural Science Foundation of the China (No. 51978436), Scientific and Technological Innovation Programs of Higher Education Institutions in Shanxi (2019L0885) and the Doctoral Startup and Research Fund of Jinzhong University.

\section{Notes and references}

1 Z. Y. Fan, Z. Y. Wang, J. W. Shi, C. Gao, G. Gao, B. R. Wang, Y. Wang, X. Chen, C. He and C. M. Niu, J. Catal., 2019, 370, 30-37.

2 C. Fang, D. S. Zhang, L. Y. Shi, R. H. Gao, H. R. Li, L. P. Ye and J. P. Zhang, Catal. Sci. Technol., 2013, 3, 803-811.

3 U. Bentrup, A. Brückner, M. Richter and R. Fricke, Appl. Catal., B, 2001, 32, 229-241.

4 J. Muñiz, G. Marbán and A. B. Fuertes, Appl. Catal., B, 2000, 27, 27-36.

5 Z. Y. Fan, J. W. Shi, C. Gao, G. Gao, B. R. Wang, Y. Wang, C. He and C. M. Niu, Chem. Eng. J., 2018, 348, 820-830.

6 B. Thirupathi and P. G. Smirniotis, J. Catal., 2012, 28, 874883.

7 S. Djerad, M. Crocoll, S. Kureti, L. Tifouti and W. Weisweiler, Catal. Today, 2006, 113, 208-214.

8 B. H. Hou, Y. L. Du, X. Z. Liu, C. Ci, X. Wu and X. M. Xie, RSC Adv., 2019, 9, 24377-24385.

9 J. P. Dunn, P. R. Koppula, H. G. Stenger and I. E. Wachs, Appl. Catal., B, 1998, 19, 103-117.

10 S. Andreoli, F. A. Deorsola, C. Galletti and R. Pirone, Chem. Eng. J., 2015, 278, 174-182.

11 X. L. Tang, J. M. Hao, W. G. Xu and J. H. Li, Catal. Commun., 2007, 8, 329-334.

12 F. Y. Gao, X. L. Tang, H. H. Yi, J. Y. Li, S. Z. Zhao, J. G. Wang, C. Chu and C. L. Li, Chem. Eng. J., 2017, 317, 20-31.

13 Z. H. Chen, Q. Yang, H. Li, X. H. Li, L. F. Wang and S. C. Tsang, J. Catal., 2010, 276, 56-65.

14 D. Fang, J. L. Xie, D. Mei, Y. M. Zhang, F. He, X. Q. Liu and Y. M. Li, RSC Adv., 2014, 4, 25540-25551.

15 M. Y. Qiu, S. H. Zhan, H. B. Yu, D. D. Zhu and S. Q. Wang, Nanoscale, 2015, 7, 2568-2577.

16 H. Meng, J. N. Liu, Y. L. Du, B. H. Hou, X. Wu and X. M. Xie, Catal. Commun., 2019, 119, 101-105.

17 Y. K. Shao, J. H. Li, H. Z. Chang, Y. Peng and Y. X. Deng, Catal. Sci. Technol., 2015, 5, 3536-3544.

18 L. Chmielarz, P. Kuśtrowski, A. Rafalska-Łasocha, D. Majda and R. Dziembaj, Appl. Catal., B, 2002, 35, 195-210.

19 Q. H. Yan, S. N. Chen, C. Zhang, D. O'Hare and Q. Wang, J. Colloid Interface Sci., 2018, 526, 63-74. 
20 X. Wu, Y. L. Feng, X. Z. Liu, L. L. Liu, Y. L. Du and Z. Li, Appl. Surf. Sci., 2019, 495, 143513.

21 Q. H. Yan, Y. Nie, R. Y. Yang, Y. H. Cui, D. O'Hare and Q. Wang, Appl. Catal., A, 2017, 538, 37-50.

22 C. Gennequin, T. Barakat, H. L. Tidahy, R. Cousin, J. F. Lamonier, A. Aboukaïs and S. Siffert, Catal. Today, 2010, 157, 191-197.

23 J. M. Gatica and H. Vidal, J. Hazard. Mater., 2010, 181, 9-18.

24 C. J. Wang and D. O'Hare, J. Mater. Chem., 2012, 22, 2306423070.

25 S. Kannan and V. Rives, J. Solid State Chem., 2004, 177, 319331.

26 C. X. Yang, L. B. Liao, G. C. Lv, L. M. Wu, L. F. Mei and Z. H. Li, J. Colloid Interface Sci., 2016, 479, 115-120.

27 D. Zhao, C. Wang, F. Yu, Y. L. Shi, P. Cao, J. M. Dan, K. Chen, Y. Lv, X. H. Guo and B. Dai, Nanomaterials, 2018, 8, 620.

28 X. J. Li, Y. L. Du, X. M. Guo, R. N. Wang, B. H. Hou and X. Wu, Catal. Lett., 2018, 149, 456-464.

29 X. Wu, Y. L. Feng, Y. L. Du, X. Z. Liu, C. L. Zou and Z. Li, Appl. Surf. Sci., 2019, 495, 14353.

30 S. P. Mo, S. D. Li, W. H. Li, J. Q. Li, J. Y. Chen and Y. F. Chen, J. Mater. Chem. A, 2016, 4, 8113-8122.

31 Q. M. Jia, S. Y. Shan, L. H. Jiang, Y. M. Wang and D. Li, J. Appl. Polym. Sci., 2012, 125, 3560-3566.

32 F. D. Liu and H. He, J. Phys. Chem. C, 2010, 114, 1692916936.

33 S. N. Chen, Q. H. Yan, C. Zhang and Q. Wang, Catal. Today, 2019, 327, 81-89.

34 Y. Nie, Q. H. Yan, S. Chen, D. O'Hare and Q. Wang, Catal. Commun., 2017, 97, 47-50.
35 B. Meng, Z. B. Zhao, X. Z. Wang, J. J. Liang and J. S. Qiu, Appl. Catal., B, 2013, 129, 491-500.

36 X. Wu, Y. L. Feng, Y. L. Du, X. Z. Liu, C. L. Zou and Z. Li, Appl. Surf. Sci., 2019, 467, 802-810.

37 F. Y. Gao, X. L. Tang, H. H. Yi, S. Z. Zhao, J. G. Wang, Y. R. Shi and X. M. Meng, Appl. Surf. Sci., 2018, 443, 103-113.

38 H. Meng, J. N. Liu, Y. L. Du, B. H. Hou, X. Wu and X. M. Xie, Catal. Commun., 2019, 119, 101-105.

39 C. Z. Sun, J. Zhu, Y. Y. Lv, L. Qi, B. Liu, F. Gao, K. Q. Sun, L. Dong and Y. Chen, Appl. Catal., B, 2011, 103, 206-220.

40 J. F. Lamonier, A. B. Boutoundou, C. Gennequin, M. J. PérezZurita and S. Siffert, Catal. Lett., 2007, 118, 165-172.

41 S. X. Cai, D. S. Zhang, L. Y. Shi, J. Xu, L. Zhang, L. Huang, H. R. Li and J. P. Zhang, Nanoscale, 2014, 6, 7346-7353.

42 X. Wu, H. Meng, Y. L. Du, J. N. Liu, B. H. Hou and X. M. Xie, ACS Appl. Mater. Interfaces, 2019, 11, 32917-32927.

43 K. I. Hadjiivanov, Catal. Rev., 2000, 42, 71-144.

44 F. D. Liu, H. He, Y. Ding and C. B. Zhang, Appl. Catal., B, 2009, 93, 194-204.

45 L. J. Yan, Y. Y. Liu, H. Hu, H. R. Li, L. Y. Shi and D. S. Zhang, ChemCatChem, 2016, 8, 2267-2278.

46 S. C. Xiong, Y. Liao, X. Xiao, H. Dang and S. J. Yang, J. Phys. Chem. C, 2015, 119, 4180-4187.

47 G. S. Qi and R. T. Yang, J. Catal., 2003, 217, 434-441.

48 G. S. Qi, R. T. Yang and R. Chang, Appl. Catal., B, 2004, 51, 93-106.

49 R. H. Gao, D. S. Zhang, P. Maitarad, L. Y. Shi, T. Rungrotmongkol, H. R. Li, J. P. Zhang and W. G. Cao, J. Phys. Chem. C, 2013, 117, 10502-10511.

50 X. N. Lu, C. Y. Song, S. H. Jia, Z. S. Tong, X. L. Tang and Y. X. Teng, Chem. Eng. J., 2015, 260, 776-784. 